\title{
The prognostic value of serum and urine amylase levels and blood count parameters in assessing the risk of post-endoscopic pancreatitis development
}

\author{
Andrzej Jamry \\ Surgical Department, District Hospital, Starachowice, Poland
}

Gastroenterology Rev 2021; 16 (2): 132-135

DOI: https://doi.org/10.5114/pg.2021.106664

Key words: endoscopic retrograde cholangiopancreatography, pancreatitis, early diagnosis.

Address for correspondence: Andrzej Jamry MD, MC, Surgical Department, District Hospital, 70 Radomska St, 27-200 Starachowice, Poland, phone: +48 602795 259, e-mail: jamry@tlen.pl

\begin{abstract}
Introduction: Detection of post-endoscopic pancreatitis (PEP) in the first hours after endoscopic retrograde cholangiopancreatography (ERCP) can limit its consequences, while excluding it can provide safe discharge of the patient. Therefore, a simple, clinically available test is needed for this purpose.

Aim: The assessment of the risk of PEP development based on serum and urine amylase levels and parameters included in blood counts $4 \mathrm{~h}$ after ERCP.

Material and methods: The study included 398 patients after therapeutic ERCP. Four hours after the procedure was completed, serum and urine amylase levels and blood count parameters were analysed.

Results: The optimal serum amylase level for PEP detection was $516 \mathrm{UI} / \mathrm{l}$, with $\mathrm{ACC}=0.94$, sens. $77.8 \%$, spec. 0.95; positive predictive value (PPV) 0.412, negative predictive value (NPV) 0.98, positive likelihood factor (LR+) 14.93, and negative likelihood factor (LR-) 0.23. The serum amylase level for exclusion of PEP was $184 \mathrm{UI} / \mathrm{I}$ with ACC 0.79, sens. 0.83, spec. 0.79, PPV 0.16, NPV 0.99 , and LR- 0.21. The optimal urine amylase level for detection and exclusion (based on Youden index) was $575 \mathrm{UI} / \mathrm{l}$, sens. 83.33\%, spec. 81.3\%, PPV 0.172, NPV 0.99, LR+ 4.44, and LR-0.20.

Conclusions: Serum amylase levels above $516 \mathrm{UI} / \mathrm{l}$ at $4 \mathrm{~h}$ after ERCP should be an indication for further observation in hospital, and levels below $184 \mathrm{UI} / \mathrm{l}$ may justify safe discharge of the patient. Additional determinations of urine amylase levels and parameters included in blood counts do not improve the diagnostic capacity for the detection or exclusion of PEP risk.
\end{abstract}

\section{Introduction}

The most common complication of endoscopic retrograde cholangiopancreatography (ERCP) is post-endoscopic pancreatitis (PEP), which affects $1.3-5 \%$ of patients [1]. PEP is associated with an almost 2-fold higher mortality rate in comparison to other forms of acute pancreatitis [2]. Detection of PEP in the first hours after ERCP and implementing early treatment can limit its consequences [3, 4]. Simultaneously, excluding PEP at this early post-procedural stage can provide a basis for safely discharging the patient. Unfortunately, the diagnosis of PEP within a few hours after procedure based on clinical symptoms, typically pain, nausea and vomiting, is not possible, because these symptoms also often occur in patients who are not developing PEP. Furthermore, almost $30 \%$ of respondents with developing
PEP do not feel any discomfort for the first $2 \mathrm{~h}$ after ERCP [5-7]. These observations indicate the need for a simple, clinically available test that allows both early detection and reliable exclusion of developing PEP $[5,8]$. Based on current clinical practice and published research, the simplest method is to determine serum amylase levels $4 \mathrm{~h}$ after the procedure was performed [9-11]. However, there is much variability regarding the reported optimal diagnostic cut-off points for detection (ranging from 300 to $1200 \mathrm{U} / \mathrm{l}$ ) and exclusion (ranging from 150 to $300 \mathrm{U} / \mathrm{l}$ ) of the disease [5, 6, 10-13]. The present study sought to address these discrepancies by reassessing the prognostic value of serum amylase levels tested $4 \mathrm{~h}$ after completion of the procedure and determining the optimal cut-off points for disease prediction and exclusion. Unlike previous studies, the analysis described here used the positive likelihood ratio 
$(\mathrm{LR}+)$ and negative likelihood ratio (LR-), which provide a better estimation of the risk of disease development in the case of asymmetrical distribution of the sample data. In addition, the simultaneous determination of urine amylase levels and parameters comprising routine blood counts, including haemoglobin (Hgb), haematocrit (HCT), leukocyte, and erythrocyte counts, after $4 \mathrm{~h}$ was evaluated for potential improvement of diagnostic efficiency [7, 14].

\section{Aim}

The aims of the study were to assess the prognostic value of serum and urine amylase levels, as well as of parameters comprising blood counts (haemoglobin (Hgb), hematocrit (HCT), leukocytes, and erythrocytes) determined $4 \mathrm{~h}$ after ERCP, for the diagnosis of the development of PEP, and to determine the cut-off point for diagnosis of disease development and its exclusion using $\mathrm{LR}+$ and $\mathrm{LR}-$.

\section{Material and methods Material}

The study included a total of 398 patients with a previously intact papillae of Vater and who had undergone therapeutic ERCP. The exclusion criteria were sphincter of Oddi dysfunction and/or elevated pre-operative amylase. The average patient age was 66 years. Within this case series, 215 (54.0\%) patients presented with systemic disease, including cancer (175 patients, $43.9 \%$ ), liver disease (67 patients, $16.8 \%$ ), cardiovascular disease (81 patients, $20.4 \%$ ), pancreatic disease (41 patients, $10.3 \%$ ), diabetes (34 patients, $8.5 \%$ ), kidney disease (27 patients, $6.8 \%$ ), central nervous system (CNS) disorders (17 patients, 4.3\%), and other diseases (56 patients, $14.1 \%$ ). Indications requiring surgery included biliary calculi in 225 (56.5\%) patients, stenosis of the ommon bile duct in 123 patients $(30.8 \%$, of which $16.0 \%$ occurred at the level of the Vater's papillae, $4.0 \%$ at the distal section, $5.5 \%$ at the level of the liver cavity and $4.2 \%$ appeared to be multilevel), and post-operative bile leakage in $6(1.5 \%)$ patients. The diameter of the bile duct, measured at a distance of $20 \mathrm{~mm}$ from the papillae, did not exceed $9.0 \mathrm{~mm}$ in 68 (17.1\%) patients. A distal segment narrower than $5 \mathrm{~mm}$ was found in 134 patients (33.7\%).

\section{Methods}

Serum and urine amylase levels, as well as blood counts, were determined $4 \mathrm{~h}$ after completion of the ERCP procedure. Additional data sources included the ENDOBASE endoscopic database, Oracle hospital database, and medical documentation from other centres.
As a diagnostic endpoint, PEP was defined as the novel development or exacerbation of abdominal pain lasting for more than $24 \mathrm{~h}$ after surgery, requiring hospitalization, and characterized by a more than 3 -fold increase in serum amylase [15].

\section{Statistical analysis}

Data were processed and analysed using the Wilcoxon rank sum test, Student's $t$ test, $\chi^{2}$ test, Fisher's test, as well as single and multivariate logistic regression curves. The Youden index was used to define cut-off points for the detection and exclusion of disease, characterizing the condition in terms of accuracy (ACC), sensitivity, specificity, positive predictive value (PPV), negative predictive value (NPV), LR+, and LR-, based on the specificity in/ sensitivity out (SpIN/SnOut) principle [16].

\section{Results}

The average level of serum amylase detected $4 \mathrm{~h}$ after surgery was $185.9 \mathrm{UI} / \mathrm{l}$, with a median of 64.0 $\mathrm{UI} / \mathrm{l}$, minimum (Min) at $5.0 \mathrm{UI} / \mathrm{l}$, and maximum (Max) at $5144.0 \mathrm{UI} / \mathrm{l}$. The area under the curve (AUC) was 0.884 and the $p<0.0001$. The average level of amylase in urine detected $4 \mathrm{~h}$ after the procedure was $703.2 \mathrm{UI} / \mathrm{l}$, with a median of $204.5 \mathrm{UI} / \mathrm{l}$, min of $12.0 \mathrm{UI} / \mathrm{l}$, and max of $19605.0 \mathrm{UI} / \mathrm{l}$. The calculated AUC value was 0.825 and $p<0.001$. The average cell count of leukocytes after $4 \mathrm{~h}$ was 8707 per microliter $(\mu \mathrm{l})$, with a median of $8100 / \mu \mathrm{l}$, min of $2200 / \mu \mathrm{l}$ and max of $26,900 / \mu \mathrm{l}$. The AUC value was 0.522 and $p=0.67$. HCT after $4 \mathrm{~h}$ had a mean of $35.4 \%$, median of $36.1 \%$, min of $20.0 \%$, and max of $47.6 \%$. The calculated AUC was 0.660 and $p=0.0249$. Erythrocyte count after $4 \mathrm{~h}$ showed a mean of $4.1 \times 10^{6} / \mu \mathrm{l}$, a median of $4.1 \times 10^{6} / \mu \mathrm{l}$, min of $1.4 \times 10^{6} / \mu \mathrm{l}$, and $\max$ of $5.49 \times 10^{6} / \mu \mathrm{l}$. The calculated AUC was 0.638 and $p=0.0129$. Hgb levels after $4 \mathrm{~h}$ had a mean of $12.2 \mathrm{~g} / \mathrm{dl}$, median of $12.2 \mathrm{~g} / \mathrm{dl}$, min of $1.2 \mathrm{~g} / \mathrm{dl}$, and $\max$ of 40.1 $\mathrm{g} / \mathrm{dl}$. The calculated AUC was 0.585 with $p=0.2445$. In the first stage, univariate logistic regression values were calculated for the risk of PEP development, as shown in Table I.

These results indicate that the risk of developing PEP $4 \mathrm{~h}$ after the procedure is more than 30-fold higher if the level of amylase $4 \mathrm{~h}$ after the procedure exceeds 5 times the normal level (> $400 \mathrm{UI} / \mathrm{l}$ ). However, a level of amylase in urine that exceeds the normal level by more than 3-fold (approx. $960 \mathrm{UI} / \mathrm{l}) 4 \mathrm{~h}$ after the procedure is associated with a more than 9-fold increased risk of developing PEP. For other variables, the calculated odds ratio $(O R)$ values were not statistically significant. Multivariate logistic regression was used to determine whether the use of several available variables would increase the prognostic value of pa- 
Table I. Univariate logistic regression values

\begin{tabular}{lcc} 
Variable $($ after $\mathbf{4}$ h) & OR & $\boldsymbol{P}$-value \\
\hline Amylase serum $>5 \times$ norm & 33.83 & $<0.0001$ \\
\hline Amylase urine $>3 \times$ norm & 9.88 & 0.004 \\
\hline Leukocytes & 0.97 & 0.7231 \\
\hline HCT & 1.12 & 0.938 \\
\hline Hgb & 1.25 & 0.7501 \\
\hline Erythrocytes & 2.33 & 0.0539
\end{tabular}

rameters predicting PEP development. The results are presented in Table II.

The calculated values were statistically significant only for the level of amylase in the blood serum exceeding normal levels by 5 -fold ( $>400 \mathrm{UI} / \mathrm{l}$ ), but the OR was 27.06. Therefore, it should be stated that the use of additional parameters (serum and urine amylase levels, Hgb, HCT, leukocytes, and erythrocytes) does not appear to improve the accuracy of PEP detection at an early stage after ERCP. The Youden index was calculated to determine the cut-off point for serum amylase to detect and exclude PEP. On this basis, it was found that the optimal serum amylase value $4 \mathrm{~h}$ after convergence is 516 $\mathrm{UI} / \mathrm{l}$, characterized by $\mathrm{ACC}=0.94$, sensitivity $=77.8 \%$, $\mathrm{PPV}=0.412$, and $\mathrm{LR}+=14.93$. In terms of disease exclusion, $516 \mathrm{UI} / \mathrm{I}$ has a specificity of $95 \%$, NPV $=0.98$, and $L R-=0.23$. Based on the analysis using the SpIn/ SnOut principle, this value is much better in detecting the disease than excluding it. Therefore, based on LRvalues, $184 \mathrm{UI} / \mathrm{l}$ was used to exclude the disease, which has a sensitivity of $83.3 \%, N P V=0.99$, and LR- $=0.21$. The level of urine amylase was analysed using the same methods as for serum amylase. Based on the Youden index test, the highest ACC was $575 \mathrm{UI} / \mathrm{I}$ with a sensitivity of $83.33 \%$, PPV 0.172, and a LR+ 4.44. All calculated values had lower ACC for detecting the disease compared with the serum amylase levels. In terms of disease exclusion, values below $575.0 \mathrm{UI} / \mathrm{l}$ had a specificity of $81.3 \%$, NPV 0.99 , and LR- 0.205. Values in this range also exhibited lower ACC for disease exclusion as compared with serum values.

\section{Discussion}

Based on the above analyses, it was determined that the serum amylase levels above which the patient should be observed in hospital is $516 \mathrm{UI} / \mathrm{I}(\mathrm{ACC}=0.94$, sensitivity $=77.8 \%$, specificity $=95 \%$, PPV $=0.412$, and $L R+=14.93)$. Conversely, safe discharge of patients may be suggested by amylase levels below $184 \mathrm{UI} / \mathrm{l}$.

Comparing these results with other published data, it should be noted that there are significant discrepancies regarding the levels of amylase that best predict or
Table II. Multivariate logistic regression

\begin{tabular}{lcc} 
Variable after $\mathbf{4} \mathbf{h}$ & OR & $\boldsymbol{P}$-value \\
\hline Amylase serum $>5 \times$ norm & 27.06 & $<0.001$ \\
\hline Amylase urine $>3 \times$ norm & 1.37 & 0.72 \\
\hline Leukocytes $>$ norm & 1.03 & 0.73 \\
\hline HCT $>$ norm & 1.15 & 0.39 \\
\hline Hgb $>$ norm & 0.81 & 0.8 \\
\hline Erythrocytes $>$ norm & 0.83 & 0.88
\end{tabular}

exclude the development of PEP. Minakari et al. analysed the relationship between amylase levels and disease development in 300 patients and concluded that $839.5 \mathrm{IU} / \mathrm{l}$ (with a specificity of $95.1 \%$, AUC $=0.978$, and 95\% Cl: 0.964-0.992) was an appropriate cut-off that justifies intensive treatment [9]. However, Thomas et al. asserted that the indication for hospitalization should be a value exceeding normal levels by 3 -fold (240 UI/I) to 6 -fold $(480 \mathrm{UI} / \mathrm{l})[5,6,12]$, which is characterized by a PPV of $90.0 \%[5,6]$. LaFerla et al. reported that in patients with amylase levels exceeding $1200 \mathrm{UI} / \mathrm{I}$ after $4 \mathrm{~h}$ or who develop PEP, hyperamylasaemia higher than $300 \mathrm{UI} / \mathrm{l}$ occurs after $1 \mathrm{~h}$. However, it is only after $2 \mathrm{~h}$ that it is possible to diagnose patients with developing PEP on the basis of amylase levels below $800 \mathrm{UI} / \mathrm{I}$ [11]. In terms of disease exclusion, the data indicated a cut-off value of $184 \mathrm{UI} / \mathrm{l}$, which translated into an almost 5-fold lower risk of developing PEP, characterized by sensitivity $=83.3 \%$, specificity $=0.79 \%, N P V=0.99$, and $L R-=0.23$.

Another study showed that an amylase value not exceeding 1.5-fold the normal value $(<120 \mathrm{UI} / \mathrm{l})$ has an NPV of $100 \%$ and can be a usable criterion for discharging a patient [5]. However, if the amylase value after $4 \mathrm{~h}$ is 5 -fold higher than normal ( $480 \mathrm{UI} / \mathrm{l}$ ), almost $30 \%$ of patients discharged may develop PEP $[5,6,10]$. In patients with amylase levels between $184 \mathrm{UI} / \mathrm{l}$ and $516 \mathrm{UI} / \mathrm{l}$, decisions regarding further management should be individualized and depend on the coexistence of other risk factors for the development of PEP. Similar recommendations presented by Testoni et al. suggested that in patients with a value range between 1.5 -fold (120 UI/l) and 3-fold (240 UI/l) above the normal level of serum amylase, the type of management should be determined by the clinical picture and coinciding risk factors $[1,5,15]$. Similarly, Lee et al. showed that amylase levels below 1.5 -fold normal levels $(<120 \mathrm{UI} / \mathrm{l})$ after $4 \mathrm{~h}$ is effective in excluding PEP with a sensitivity of $93 \%$, and a value 4-fold higher than normal (> $320 \mathrm{UI} /$ ) should be an indication for preventive therapy, with $93.2 \%$ sensitivity [17]. In yet another study, Park et al. proposed that where amylase levels are lower than 1.5-fold above nor- 
mal $4 \mathrm{~h}$ after the procedure, enteral nutrition may help reduce the costly supplementary medical care needed after ERCP [18].

The variation in data between different studies may be due to several factors. First, statistical methods were used to determine cut-off points. Most studies used PPV and NPV, whereas our study (based on suggestions made by collaborating statisticians) used likelihood ratios LR+ and LR-, which in the case of asymmetry of the studied groups seem to better assess the existing risk. The second factor may be the inclusion criteria, which limited the analysis to patients who had previously had intact papillae of Vater and underwent ERCP therapeutic procedures (all had endoscopic sphincterotomy).

\section{Conclusions}

Serum amylase levels above $516 \mathrm{UI} / \mathrm{l}$ at $4 \mathrm{~h}$ after ERCP should justify hospitalization of the patient. Serum amylase levels below $184 \mathrm{UI} / \mathrm{l} 4 \mathrm{~h}$ after ERCP suggest safe discharge of the patient for further outpatient treatment. Additional determination of urine amylase levels and blood count parameters do not improve the ability to predict or exclude PEP.

\section{Conflict of interest}

The author declares no conflict of interest.

\section{References}

1. Dumonceau J-M, Andriulli A, Deviere J, et al. European Society of Gastrointestinal Endoscopy (ESGE) Guideline: prophylaxis of post-ERCP pancreatitis. Endoscopy 2010; 42: 503-15.

2. Testoni PA, Vailati C, Giussani A, et al. ERCP-induced and non-ERCP-induced acute pancreatitis: two distinct clinical entities with different outcomes in mild and severe form? Dig Liver Dis 2010; 42: 567-70.

3. DiMagno M, Wamsteker E, Maratt J, et al. Do larger periprocedural fluid volumes reduce the severity of post endoscopic retrograde cholangiopancreatography pancreatitis? Pancreas 2014; 43: 642-7.

4. Shaygan-Nejad A, Masjedizadeh AR, Ghavidel A, et al. Aggressive hydration with lactated ringer's solution as the prophylactic intervention for post endoscopic retrograde cholangiopancreatography pancreatitis: a randomized controlled double-blind clinical trial. J Res Med Sci 2015; 20: 838-43.

5. Thomas PR, Sengupta S. Prediction of pancreatitis following endoscopic retrograde cholangiopancreatography by the 4-h post procedure amylase level. J Gastroenterol Hepatol 2001; 16: 923-26.

6. Gottlieb K, Sherman S, Pezzi J, et al. Early recognition of post-ERCP pancreatitis by clinical assessment and serum pancreatic enzymes. Am J Gastroenterol 1996; 91: 1553-61.

7. Testoni PA, Bagnolo F, Caporiscio S, et al. Serum amylase measured four hours after endoscopic sphincterotomy is a reliable predictor of postprocedural pancreatitis. Am J Gastroenterology 1999; 94: 1235-41.
8. Tenner S. Initial management of acute pancreatitis: critical issues during the first 72 hours. Am J Gastroenterol 2004; 99 : 2489-94.

9. Minakari M, Sebghatollahi V, Sattari M, et al. Serum amylase and lipase levels for prediction of postendoscopic retrograde cholangiopancreatography pancreatitis. J Res Med Sci 2018; 23: 54-7.

10. Testoni PA, Caporuscio S, Bagnolo F, et al. Twenty-four-hour serum amylase predicting pancreatic reaction after endoscopic sphincterotomy. Endoscopy 1999; 31: 131-6.

11. LaFerla G, Gordon S, Archibald M, et al. Hyperamylasaemia and acute pancreatitis following endoscopic retrograde cholangiopancreatography. Pancreas 1986; 1: 160-3.

12. Testoni PA. Preventing post-ERCP pancreatitis: where are we? JOP 2003; 4: 22-32.

13. Ito K, Fujita N, Noda Y, et al. Relationship between post-ERCP pancreatitis and the change of serum amylase level after the procedure. World J Gastroenterol 2007; 13: 3855-60.

14. Baillargeon JD, Orav J, Ramagopal V, et al. Hemoconcentration as an early risk factor for necrotizing pancreatitis. Am J Gastroenterol 1998; 93: 2130-4.

15. Christoforidis E, Goulimaris I, Kanellos I, et al. Post-ERCP pancreatitis and hyperamylasemia: patient-related and operative risk factors. Endoscopy 2002; 34: 286-92.

16. Sackett, DL, Hayes, RB, Guyatt, G, et al. Clinical Epidemiology: A Basic Science for Clinical Medicine. Second Edition. Lippincott Williams and Wilkins, Little, Brown and Company, Boston, MA. 1991.

17. Lee Y, Yang M, Kim S, et al. Prediction of post-endoscopic retrograde cholangiopancreatography pancreatitis using 4-hour post endoscopic retrograde cholangiopancreatography serum amylase and lipase levels. J Korean Med Sci 2017; 32: 1814-9.

18. Park CH, Jung JH, Hyun B, et al. Safety and efficacy of early feeding based on clinical assessment at 4 hours after ERCP: a prospective randomized controlled trial. Gastrointestinal Endosc 2018; 87: 1040-9.

Received: 22.04 .2020

Accepted: 30.06 .2020 